\title{
Análise do não uso do laboratório de informática nas escolas públicas e estudo de caso. ${ }^{*}$
}

\author{
Elizandra K. Odorico, Denilson M. Nunes, Alex Moreira, Helen M. P. de Oliveira, \\ Andréa Cardoso
}

\author{
${ }^{1}$ Instituto de Ciências Exatas - Universidade Federal de Alfenas (UNIFAL-MG) \\ 37.130-000 - Alfenas - MG - Brasil \\ li.elizandra@gmail.com, denilsonmiranda29@hotmail.com, \\ alexmoreirall@hotmail.com, helen.pedrosa@yahoo.com.br, andreac74@uol.com
}

\begin{abstract}
This paper presents a study performed in two public schools in order to investigate the conception of teachers in relation to the physical structure of schools and computer labs, the use of these spaces and appropriation of new technologies of information and communication in planning and implementing lessons. We conclude that the greatest challenge is the integration of computational resources in the educational project of the school and the encouragement of appropriation of digital culture by teachers.
\end{abstract}

Resumo. Este trabalho apresenta uma pesquisa desenvolvida em duas escolas públicas com o objetivo de investigar a concepção dos professores em relação à estrutura física das escolas e laboratórios de informática, a utilização desses espaços e apropriação das novas tecnologias da informação e comunicação no planejamento e execução das aulas. Conclui-se que o maior desafio é a inserção dos recursos computacionais no projeto pedagógico da escola e o incentivo à apropriação da cultura digital por parte dos professores.

\section{Introdução}

Atualmente, a informática cresce em uso e relevância em todo o mundo possibilitando trazer inúmeros desenvolvimentos de atividades diferenciadas para a sala de aula. As atividades utilizando recursos computacionais podem contribuir de forma efetiva para o processo ensino aprendizagem, desde que haja contribuição dos programas governamentais, apoio técnico, capacitação e planejamento dos educadores. No entanto, os professores que se dispõe utilizar tecnologias digitais se deparam com várias dificuldades na elaboração e implementação das atividades na escola.

Segundo Almeida (2000) o processo de informatização é uma realidade nas instituições escolares. Embora as escolas brasileiras estejam ampliando e criando espaços multimídia e também a utilização de tecnologias digitais na própria sala de aula. Entretanto, muitos professores encontram dificuldades em utilizar estas novas tecnologias na preparação e execução de suas aulas, nas diversas áreas. Talvez por que estejam sendo inserido em um espaço que não lhes é familiar e para o qual não foram preparados, sendo

${ }^{*}$ O presente trabalho foi realizado com apoio financeiro do Programa Institucional de Bolsas de Iniciação à Docência (PIBID), da Coordenação de Aperfeiçoamento de Pessoal de Nível Superior (CAPES) e da Fundação de Amparo a Pesquisa do Estado de Minas Gerais (FAPEMIG). 
assim, concentram-se em aulas tradicionais e quando utilizam a tecnologia reproduzem a mesma metodologia.

Muitos professores se sentem inseguros quando trabalham com seus alunos no laboratório de informática, pois sabem que estes dominam a máquinas e as ferramentas mais do que eles. Assim, os professores optam simplesmente por indicar um tema para pesquisa, dando implicitamente liberdade para o aluno navegar pela rede, o que fatalmente provoca mudança de foco. Neste cenário como novos instrumentos é papel da escola, do sistema de ensino e do professor acompanhar e orientar o aprendiz.

Assim, com o contato adquiridos nas escolas públicas parceiras do Programa Institucional de Bolsa à Iniciação a Docência (PIBID) foi observada que a utilização dos Laboratórios de Informática pelos educadores é mínima. Desta forma, o artigo tem como objetivo descobrir porque os educadores não reconhecem e também não utilizam este espaço para fins pedagógicos. Nessa perspectiva, descrevemos a metodologia da pesquisa, apresentamos a sistematização e análise dos dados, apresentou um estudo de caso relacionado ao uso da tecnologia digital em sala de aula e, enfim as considerações finais.

\section{Utilização dos Laboratórios de Informática nas Escolas}

Desde a década de 1970, com a evolução tecnológica, vem se aplicando teorias de aprendizagem relacionadas com o uso de computadores na educação. Papert (1985) defende o uso de computadores para provocar mudanças na educação, sugerindo a realização de atividades que fogem da proposta convencional da escola, acredita que o ensino deve ser centrado no aluno, no desenvolvimento de estratégias de raciocínio, na conscientização do próprio processo de aprendizagem, na pedagogia de projetos e na aprendizagem cooperativa, através da qual ele é capaz de criar.

Muitas instituições que inseriram Laboratórios de Informática em seu meio não conseguiram realizar as modificações esperadas, sendo estes espaços considerados na maioria dos casos enfeites, "basicamente como 'enfeites' de técnicas tradicionais de ensino, dourando a pílula, tornando o ensino tradicional mais atraente"(Cysneiros, 1999).

A presença de computadores na escola faz com que as pessoas que os utiliza acreditem que ela por si só irá resolver os problemas existentes na escola. É importante que o uso destes computadores esteja incorporado ao projeto educativo, deixando de ser uma ação isolada. "Inovações tecnológicas não determinam inovações pedagógicas. Melhores recursos não implicam melhores desempenhos"(Amaral, 2006).

O uso de computadores pode contribuir decisivamente na ação de levar os estudantes à descoberta e à construção do conhecimento. No caso, do ensino e aprendizagem de matemática poderá ser vista não como um ato mecânico, mas com os recursos multimídia o educador poderá mostrar uma melhor visualização de conteúdos propostos. $\mathrm{O}$ impacto da tecnologia, cujo instrumento mais relevante é o computador, exigirá do ensino de Matemática um redirecionamento sob uma perspectiva curricular que favoreça $o$ desenvolvimento de habilidades e procedimentos com os quais o indivíduo possa se reconhecer e se orientar nesse mundo do conhecimento em constante movimento. Sendo assim, compete à Escola e aos Educadores, mais que a ninguém, assumir e incorporar esta ferramenta de trabalho, de modo a fazer com que o computador seja colocado a serviço da Educação, da mudança de paradigma desejada e referida nos Parâmetros Curriculares Nacionais e de seus objetivos. 


\section{A dinâmica da pesquisa}

A pesquisa foi realizada por meio de um questionário, sendo este aplicado para maioria dos professores das duas escolas, durante um mês para aplicar e recolher o documento, sendo que foi disponibilizado aos educadores um tempo para responderem. Dois tipos de questionário foram confeccionados, um geral outro específico para professores de matemática. Os professores de matemática responderam os dois. O geral apresentou quatorze questões, sendo estas doze múltiplas escolhas e duas check-list, já o específico tinha três indagações uma de múltipla escolha e duas check-list. Para aprofundar e analisar a pesquisa foi utilizado um instrumento auxiliar, como a planilha eletrônicas para registrar as respostas obtidas e gerar os gráficos.

$\mathrm{Na}$ análise geral das duas escolas os dados serão apresentados na mesma ordem, por escola: primeira escola e segunda escola. As duas instituições de ensino analisadas são escolas da rede estadual de ensino, com uma unidade de ensino tradicional de uma cidade de médio porte localizada no interior do estado, a partir de agora denominada apenas de primeira escola. A outra instituição está também localizada na região central da cidade, porém é de menor porte, com condições mais precárias e atende um público de classe social mais baixa, que será denominada segunda escola.

A primeira escola atende 1020 estudantes do ensino médio, conta com 77 professores e, desde 1998 possui 2 laboratórios de informática equipados com 34 computadores ao todo com acesso à internet. Já a segunda escola atende 580 alunos do ensino fundamental e médio, conta com 34 educadores e, desde 2008 possui 1 laboratório de informática equipado com 19 computadores acesso à internet.

\section{Análise da concepção dos professores quanto ao uso do laboratório de informática}

A análise do questionário revelou que, em sua maioria, a formação inicial do professor não contemplou tópicos relacionados ao uso da informática no ensino. Apenas $14 \%$ dos docentes da primeira escola e $11 \%$ dos docentes da segunda escola afirmaram que tenham participado de algum curso relacionados à recursos computacionais em sua formação. Quando indagados sobre sua formação continuada e capacitação em serviço, $50 \%$ do total de professores declaram buscar atualização com cursos de informática, os mais citados foram: Linux Básico, Sistemas operacionais e Java. A outra metade dos professores justifica que não participaram de cursos nesta área devido a sua extensiva jornada de trabalho ou mesmo por falta de recursos financeiros.

Os professores foram questionados quanto ao conhecimento da quantidade de salas de informática que a escola possui. Os dados coletados na primeira escola, de acordo com a Figura 1 primeiro gráfico, explicita o desconhecimento da estrutura física da escola por parte dos professores. Por outro lado, os professores da segunda escola foram unânimes em responder que há um laboratório, demonstrando o espaço físico que trabalham, em relação aos recursos computacionais.

Podemos observar que na primeira escola somente $36 \%$ reconhecem o espaço que trabalham e provavelmente estão inseridos neste grupo aqueles que estão familiarizados com as condições dos laboratórios de informática da escola. Na questão seguinte referente às condições de infraestrutura e dos equipamentos na sala de informática, as respostas se dividem em 10\% em branco, 10\% boas condições, $20 \%$ razoável, $60 \%$ condições 


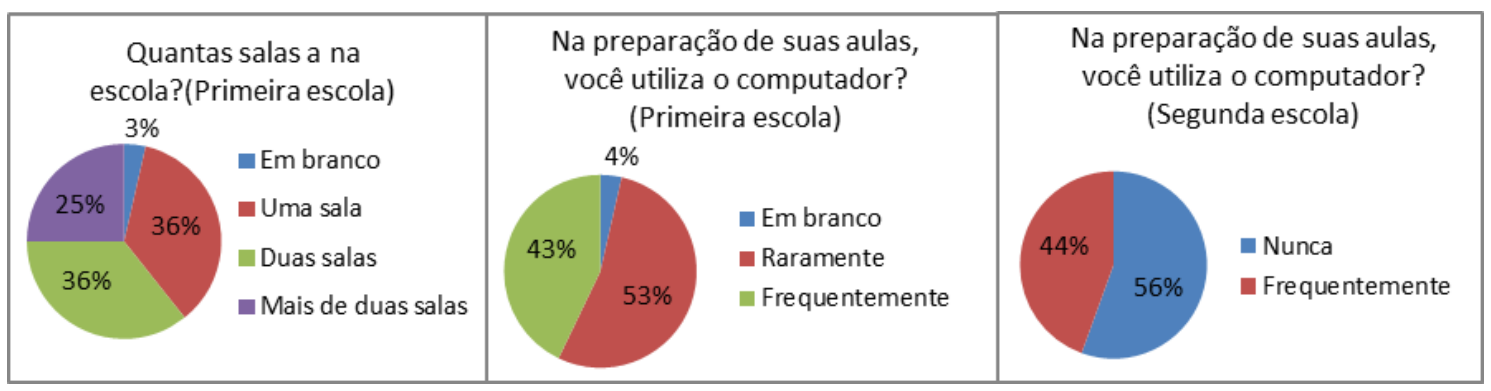

Figura 1. Representação do numero de salas na escola (gráfico a esquerda) e índice de utilização dos computadores pelos professores(segundo e terceiro gráfico da direita).

precárias. Na segunda escola, os professores também se dividiram nas respostas, $11 \%$ deles classificaram as condições da sala de informática como boa, os outros $89 \%$ afirmam que os computadores e as salas estão em condições precárias.

Outra questão abordada foi se o professor utiliza o computador para preparar suas aulas, o resultado encontra-se no gráfico apresentado na figura 1 (segundo e terceiro gráficos). Apesar do alto índice de utilização do computador, $43 \%$ do total de professores admitem sentir dificuldades em utilizar a ferramenta computacional na preparação de suas aulas, o que deixa em dúvida a real veracidade das respostas dadas na questão anterior. As principais dificuldades apontadas por este grupo é falta de tempo, insegurança e falta de habilidade com a máquina.

Um fator que pesa muito na utilização dos laboratórios é a presença na escola de um profissional da área de informática, já que muitos professores sentem-se inseguros e apresentam dificuldades para utilizar o computador. Entretanto nenhuma das instituições analisadas possui tal profissional para auxiliar os professores nas matérias específicas. Novamente os professores da primeira escola revelam o desconhecimento da estrutura de seu local de trabalho, $21 \%$ afirmam não saber se existe um profissional da área de informática, $14 \%$ disseram que há presença deste na escola, $61 \%$ afirmaram que não há e $4 \%$ simplesmente não responderam. Já na outra instituição $89 \%$ relataram que não e $11 \%$ desconhecem.

Os educadores que declaram utilizar recurso computacional na preparação de suas aulas deveriam responder se é possível identificar algum impacto no comportamento do aluno após a utilização de recursos computacionais, o resultado está ilustrado na Figura 2 .

A pesquisa mostra que em torno de $89 \%$ dos professores utiliza a internet para fins pedagógicos, citando as páginas da Secretária Estadual de Educação, Google Acadêmico, Centro de Referência Virtual do Professor e Só Matemática. Entretanto percebemos que os educadores não compreendem a questão da utilização dos computadores na preparação das aulas, visto que quando utilizam a internet já estão usando o recurso. Também afirmaram que a internet nos laboratórios é lenta.

No questionário específico para os professores de matemática foram abordadas as questões com relação à importância do computador para as aulas de matemática, e se eles foram preparados e orientados em sua graduação sobre sua importância. De modo 


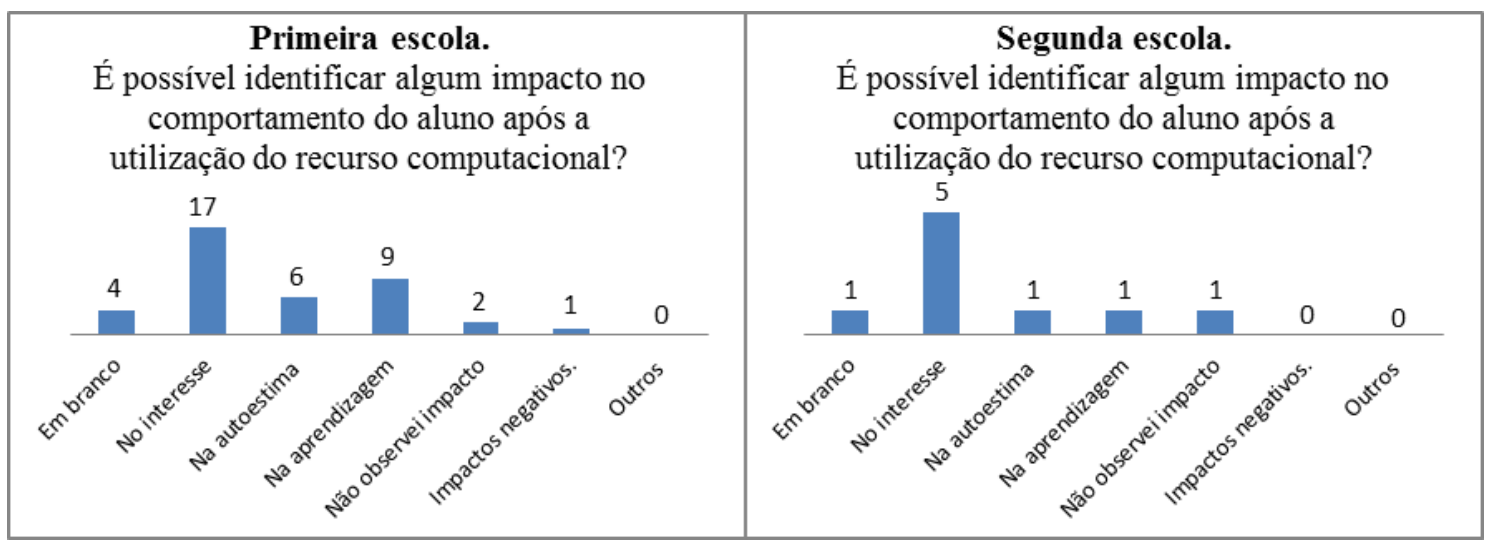

Figura 2. Gráfico representando o impacto no comportamento do aluno após a utilização dos computadores.

geral eles compreendem a necessidade da utilização deste tipo de recurso nas aulas de matemática. Já na questão sobre a formação, apenas uma professora declara ter sido preparada, as demais disseram que não.

A opinião de algumas professoras foi "O uso do computador auxilia muito no processo do ensino, porém nem sempre é possível o seu uso devido às necessidades da escola, visto que dispomos de poucas salas de áudio e falta de manutenção nos computadores.", outra professora, argumenta que,"É uma ferramenta tecnológica que pode ser utilizada com o objetivo de aumentar a eficácia do ensino, desenvolver a capacidade de observação de pesquisa e de troca de experiências e vivências."

\section{Estudo de caso}

Desde 2009, os bolsistas de iniciação à docência do curso de licenciatura em matemática atuam na primeira escola, que é uma instituição parceira da universidade na formação de professores através do PIBID. Dentro do subprojeto, uma das linhas temáticas é a análise de material didático e recursos tecnológicos para utilização em aulas de Matemática. Assim foram desenvolvidas propostas metodológicas alternativas para o ensino de Matemática pautadas pela contextualização e utilização de recursos tecnológicos, de acordo com as dificuldades e motivação observadas.

Especificamente para os futuros professores de matemática, espera-se que sejam capazes de: estabelecer relações entre os diversos conteúdos; trabalhar com as novas tecnologias da informação e da comunicação de maneira produtiva objetivando a superação de problemas e obstáculos identificados no processo ensino-aprendizagem; analisar e criticar os livros-textos de forma a construir seu próprio material didático quando necessário; propor atividades diferenciadas, contextualizadas e que promovam a interdisciplinaridade e; conceber a aprendizagem como um processo de construção e reconstrução do conhecimento, onde o certo e o errado cedem lugar a uma enorme diversidade de soluções, umas sensivelmente provisórias e outras mais elaboradas.

Apesar da escola possuir dois laboratórios de informática, os computadores estão em condições precárias para uso, a conexão com a internet é lenta, alguns computadores não funcionam adequadamente, não há programas específicos instalados e nem há a possibilidade de instalação de softwares nas máquinas devido à burocracia imposta pela 
secretaria de educação.

Diversas atividades como intervenções, minicursos e oficinas foram desenvolvidas ao longo do tempo junto a professores e estudantes desta escola, sempre se pautando pelo objetivo principal de inserir as novas tecnologias no ensino. Frente a impossibilidade de utilização dos laboratórios de informática, as atividades foram ora desenvolvidas na universidade, quando estas aconteciam em contraturno, ora adaptadas para serem trabalhadas em sala de aula.

Neste contexto, foi desenvolvida uma oficina para duas turmas de segundo ano do ensino médio totalizando dezoito aulas, sobre funções trigonométricas priorizando a utilização de recursos tecnológicos em sua concepção e aplicação na tentativa de minimizar as dificuldades encontradas no tópico abordado. Identificou-se nos aprendizes grandes dificuldades no conteúdo e isto se deve segundo Costa (1997), ao fato de que as funções trigonométricas surgem como um conteúdo vazio de sentido, uma vez que geralmente são introduzidas sem nenhuma ligação com a vida cotidiana.

No caso específico para funções trigonométricas, a primeira etapa se caracterizou pelo estudo conceitual teórico, a segunda etapa foi destinada à análise do livro didático utilizado na escola sobre o conteúdo, a terceira etapa foi dedicada a buscar uma alternativa da inserção dos recursos computacionais em sala de aula, seguida da construção do material didático, aplicação e avaliação.

Em relação ao conteúdo, o livro didático utilizado se mostrou bem superficial, e algumas vezes até incompleto, principalmente na exploração de conceitos e visualizações relacionadas à construção gráfica das funções.

A proposta de utilização dos recursos computacionais foi pensada para desenvolver atividades de exploração algébrica e gráfica dos conceitos relacionados a funções trigonométricas utilizando Objetos de Aprendizagem (OA) desenvolvidos no programa de geometria dinâmica geogebra ${ }^{1}$.

Como alternativa ao uso do laboratório, a aplicação da intervenção pedagógica se deu em sala de aula com utilização de recursos multimídia. Primeiramente, foi apresentadas a visualização de cada OA em momento adequado. Em seguida, os bolsistas faziam questionamentos sobre a situação visualizada, manipulavam os elementos do OA de forma a gerar reflexões sobre o impacto das alterações e os estudantes eram convidados a fazer anotações em seus cadernos de acompanhamento, para posteriores inferências e conclusões.

O caderno de acompanhamento pedagógico foi especialmente elaborado para esta atividade, contendo atividades estruturadas sobre os conceitos abordados, bem como definições, aplicações e exercícios.

Os OA foram utilizados em diversos momentos, como na exploração do conceito, na determinação do comportamento de crescimento e decrescimento das funções, construção gráfica, determinação do domínio, contradomínio e imagem, além da exploração do impacto causado pela variação dos coeficientes nas funções seno, cosseno e tangente, como ilustrado na Figura 3.

\footnotetext{
${ }^{1}$ software livre e de fácil manipulação, que possui ferramentas de álgebra, geometria e cálculo em português. Disponível em: http://www.geogebra.org/webstart/geogebra/html
} 

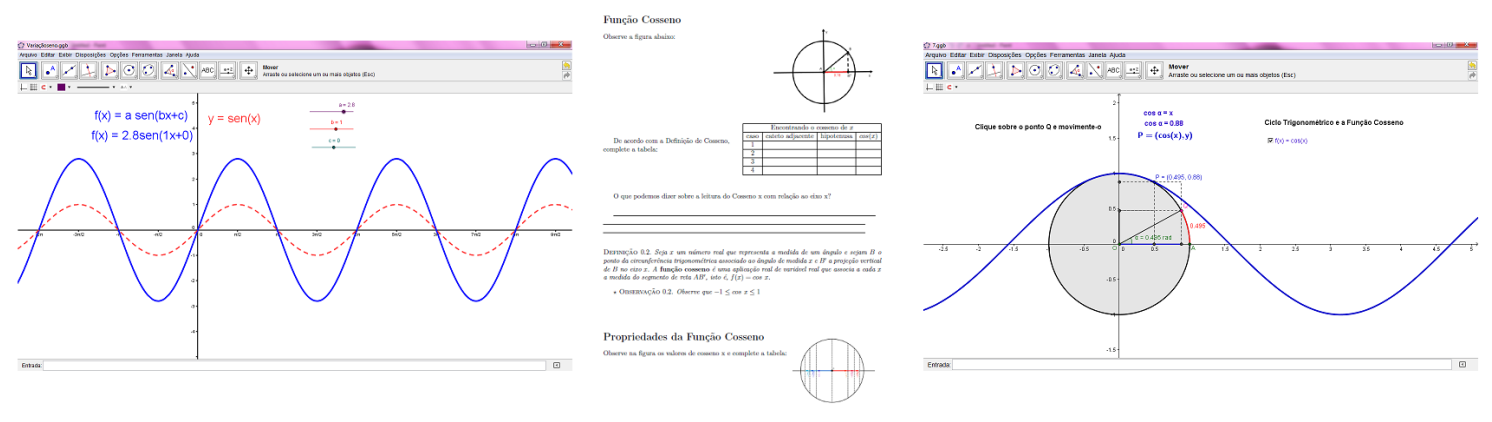

Figura 3. Instâneo de dois objetos de aprendizagem e no centro um página do caderno de acompanhamento.

De acordo com a avaliação da intervenção e com o relato dos professores que acompanharam toda a atividade, a utilização dos recursos tecnológicos e material didático específico contribuíram no processo de construção e familiarização com o conteúdo, uma vez que os estudantes possuiam apenas conhecimentos básicos de razões trigonométricas. Os professores observaram que houve aprendizado efetivo principalmente na construção e interpretação gráfica de funções e no uso da calculadora.

Com a aplicação desta oficina, constatou-se que é possível a utilização de recursos computacionais em sala de aula, mesmo que estes não estejam em local apropriado para este fim, como os laboratórios de informática. Ao longo do desenvolvimento do trabalho notou-se que atividades como esta exigem atenção e desenvolvimento de raciocínio por parte dos aprendizes que costumam apresentar certa resistência, já que a metodologia é bastante distinta daquela normalmente desenvolvida em sala, que geralmente prioriza a repetição de algoritmos em detrimento do desenvolvimento de habilidades em relação aos conceitos de funcionalidade, representação gráfica, interpretação algébrica e resolução de problemas.

Segundo Valente (2003) a formação de professores para utilizar as tecnologias digitais na educação, não exige apenas o domínio dos recursos informacionais, mas uma prática reflexiva inserida no contexto de trabalho do professor. Reafirma-se, nessa perspectiva que o uso de computadores por si só, não garante uma melhoria na qualidade do ensino e não é uma solução mágica para os problemas pedagógicos da sala de aula. Mas diante das observações feitas durante a realização da oficina, pode-se notar que é uma alternativa que pode contribuir muito para a melhoria do processo ensino-aprendizagem, mas para que isto seja possível é necessária a melhor compreensão da real importância do uso de ferramentas computacionais neste processo.

\section{Considerações finais}

Os resultados analisados apontam que falta planejamento para a inserção e o uso dos laboratórios de informática das escolas, ignorando sua importância pedagógica, sugerindo novas pesquisas e estudos sobre o tema. O maior desafio apontado pela pesquisa foi a falta de incentivo da escola e apropriação da cultura digital por parte dos professores. Em geral, o professor não recebeu formação para o uso pedagógico da ferramenta computacional e não se sentem confortáveis com o uso das novas tecnologias em sala de aula. Muitas vezes buscam, por iniciativas e recursos próprios, atualizar-se pois o estado não fornece o 
suporte e cursos adequados.

Os laboratórios de informática de algumas escolas públicas estão sendo subutilizados, mas é necessário que o computador seja colocado a serviço da educação. Para isso, os espaços destinados ao uso dos equipamentos eletrônicos nas escolas devem contar com profissionais específicos para suporte técnico e pedagógico e, principalmente reconhecidos e apropriados pelos professores. Além disso, a utilização de uma metodologia diferenciada exige bastante tempo de estudo e dedicação, desde o planejamento até a aplicação da atividade.

A vivência e prática de sala de aula e o reconhecimento dos espaços da escola por parte dos bolsistas de iniciação à docência, certamente resulta em uma formação pedagógica do futuro professor de matemática mais completa e realista. Se, por um lado, a pesquisa mostrou o completo desinteresse dos professores na utilização dos recursos computacionais, por outro, a experiência em sala de aula revelou que este recursos contribuem para o aprendizado significativo de conceitos matemáticos e que é possível buscar alternativas para inserção da tecnologia digital na sala de aula.

A comunicação mediada pela tecnologia, tanto na sala de aula quanto fora dela, traz uma nova forma de saber, fazer e pensar o processo de ensino e aprendizagem e, a questão da utilização ou não dos recursos computacionais vai além da falta de computadores nas escolas ou manutenção destes, perpassa a formação docente e mudanças na proposta pedagógica e curricular.

\section{Referências}

Almeida, M. E. (2000) Proinfo: Informática e formação de professores. Brasília: MEC/SEED.

Amaral, M. T. M. (2006) Práticas educativas informatizadas; integração das tecnologias na gestão escolar. In: (Coords.) Almeida, F. J.; Almeida, M. E. B. B. de. Liderança, gestão e tecnologia para melhoria da educação no Brasil. São Paulo: Microsoft.

Cysneiros, P.G. (1999) Resenha crítica: a máquina das crianças (Seymour Papert). Revista Brasileira de Informática na Educação, v.3, n.06, p.139-144.

Costa, N. M. L. da. (1997) Funções Seno e Cosseno: Uma sequência de ensino a partir dos contextos do "mundo experimental"e do computador (Tese de mestrado) Pontifícia Universidade Católica, São Paulo.

Nascimento, K. A. S. do et al. (2011) Um olhar sobre as atividades dos Laboratórios de Informática Educativa das escolas municipais de Fortaleza. In: SIMPÓSIO BRASILEIRO DE INFORMÁTICA NA EDUCAÇÃO, XXII, Anais... Aracajú: Sociedade Brasileira de Computação, 2011. p.1-8.

Papert, S. (1985) Logo: Computadores e educação. São Paulo: Brasiliense.

Pereira, D. A., Borges,M. K. (2011) Mídias sociais e instituições de ensino: uma ponte entre a escola e seus públicos. In: SIMPÓSIO BRASILEIRO DE INFORMÁTICA NA EDUCAÇÃO, XXII, Anais... Aracajú: Sociedade Brasileira de Computação, 2011. p.1-4.

Valente, J. A. (2003) Formação de Educadores para o uso da informática na escola. 
Campinas: UNICAMP/NIED. 